\title{
Procedural sedation in a tertiary referral trauma centre: $\mathrm{A}$ retrospective audit
}

\author{
James Falconer, Drew Richardson \\ Emergency Department, Canberra Hospital and Health Service, Garran, Australian Capital Territories; \\ Australian National University, Australian Capital Territories, Australia
}

\begin{abstract}
Procedural sedation complications are common in Australasian Emergency Departments (EDs). This study aimed to compare procedural sedation complications between The Canberra Hospital $\mathrm{ED}(\mathrm{TCH} \mathrm{ED})$ and the available Australasian literature and to determine if sedation associated complications were amenable to simple intervention. All procedural sedations performed over two and half years in TCH ED were retrospectively reviewed. Complications were defined as per the previous comparable Australasian study, as those events requiring an intervention. 1793 sedations were reviewed: 1125 (63\%) for orthopaedic procedures, other 276 (a collection of painful procedures), 208 suturing and 169 direct current cardioversions. The median age was 29 years with $538(30 \%)$ children under the age of 16 years. The complica-
\end{abstract}

Correspondence: James Falconer, Emergency Department, Canberra Hospital and Health Services, Yamba Drive, Garran, Australian Capital Territories 2605, Australia.

Tel.: +61251240000 - Fax: +61251243543.

E-mail: James.falconer@act.gov.au

Acknowledgements: the authors would like to thank Professor David Taylor, Director Emergency Medicine Research at Austin Health, Victoria for generously allowing access to the database of his 2011 research article (Taylor DM, Bell A, Holdgate A, et al. Risk factors for sedation-related events during procedural sedation in the Emergency Department. Emerg Med Australas 2011;23:466-73).1

Key words: Sedation; Procedural sedation; Complications; Emergency Department; Emergency procedures.

Contributions: JF conceived the study, acquired the data and drafted the manuscript. Both JF and DR contributed to analysing and interpreting the data, then critically evaluating and refining the manuscript.

Conflict of interest: the authors declare no potential conflict of interest.

Funding: none.

Received for publication: 9 April 2019

Revision received: 31 July 2019.

Accepted for publication: 8 August 2019.

This work is licensed under a Creative Commons Attribution 4.0 License (by-nc 4.0).

(C) Copyright: the Author(s), 2019

Licensee PAGEPress, Italy

Emergency Care Journal 2019; 15:8214

doi:10.4081/ecj.2019.8214 tion rate in the initial six-months was $4.0 \%$ dropping to $1.3 \%$ after multiple education sessions before rebounding to $3.1 \%$ in the last six-months. The overall complication rate was $3.1 \%$ (95\% CI $2.3-$ 4.0) which is significantly lower $(\mathrm{P}<0.0001)$ than the comparable previous major Australian study (7.2\%, 95\% CI 6.2-8.2). There was significantly less use of Midazolam (10.3\% vs $23.8 \%$ $\mathrm{P}<0.00001)$ and Morphine $(1.5 \%$ vs $7.9 \% \mathrm{P}<0.00001)$. There was one case of laryngospasm requiring intubation but subsequently discharged at baseline, otherwise no recorded major adverse events. Therefore procedural sedation at TCH ED has a complication rate less than that previously reported and this may be due to evolution of the agents used. The complications seem to be readily amenable to education around prevention, but the benefit of these education sessions appears to decay over time.

\section{Introduction}

Procedural sedation is an accepted part of Emergency Department (ED) practice and is considered a core competency for emergency physicians by the Australasian College of Emergency Medicine. ${ }^{1,2}$ It is performed to facilitate potentially painful procedures and involves the use of a variety of generally short acting sedative and analgesic agents with close monitoring and recording to protect the patient from adverse events. Nevertheless, sedation related events such as hypoxia, hypotension and vomiting are still commonly reported. ${ }^{1}$

In 2015 the sedation record at The Canberra Hospital (TCH), a tertiary referral hospital seeing 75,000 patients per annum, was rewritten to become a joint intubation and procedural sedation form. Sedation and intubation fall on the same continuum, as sedations are far more common than intubations the single record was intended to increased familiarity with preparation for intubation as well as bring it into line with current best practise and enable data collection. All sedations at $\mathrm{TCH}$ require at least two doctors (one airway and one procedure) and at least one nurse. The first page (preparation for sedation) is completed in a collaborative fashion by the sedation team prior to the sedation. The observations are then independently recorded by the scribe nurse during the sedation.

Education sessions on sedation for both medical and nursing staff were undertaken after six months, with the aim of highlighting sedation techniques to reduce complications.

This study was undertaken to compare procedural sedation complications between the study institution and available literature; but also to determine if sedation complications were amenable to simple intervention. 


\section{Materials and Methods}

This is a retrospective analysis of all procedural sedations recorded in the clinical records system at $\mathrm{TCH}$ over five six-month periods from the introduction of the new record. The date, reason and agent used for the sedation, age (in years or months if under one year old), fasting status of the patient, seniority of the medical team leader and any complications of the procedure were obtained. Intubations were excluded and data from the Emergency Department Information System (version EDISAPAC 12.0.3, iSoft, Sydney, Australia), observation charts and written notes were added to ensure a complete dataset.

The criteria for sedation related complications were those used by Taylor et al., ${ }^{1}$ that is those complications that required an intervention, specifically: hypoxia was a documented saturation less than $90 \%$ and hypotension was a systolic blood pressure less than $80 \mathrm{mmHg}$. Taylor ${ }^{1}$ was contacted and his studies database was then reanalysed to allow direct comparisons to be made between the two studies.

\section{Results}

A total of 1793 sedations were collected. The age range was from 6 months to 99 years with a median age of 29 years; 538 $(30 \%)$ were children under the age of sixteen years.

\section{Indications for Emergency Department sedation}

Joint relocation and fracture reduction were the most common reason for emergency sedation. The Other category while the next most common reason for sedation was a heterogeneous mix of painful procedures, for example application of cast, wound washout, intercostal catheter placement, removal of foreign bodies and wound care. Suturing (usually children) and direct current (DC) cardioversion completed the major categories.

\section{Sedation medications by age}

Fentanyl and propofol are the most commonly used combination of agents overall (670/1793), particularly in those patients older than 17 years and representing 50\% (627/1255) of all sedative agents used in these two age groups. Propofol alone was used in $12.5 \%$ (224/1793) of sedations. Ketamine and nitrous oxide are the most commonly used agents in those $\leq 16$ years, with IM ketamine almost exclusively used in this age group and representing $32 \%$ of these sedations. Ketamine (whether IV or IM) represents $46 \%$ of all agents used in those $\leq 16$ years of age, and if combined with nitrous oxide this then rises to $73 \%$. Morphine is rarely used, being used in a total of $27 / 1793$ cases. Midazolam $(184 / 1793)$ was mainly used as a low dose pre-procedural anxiolytic for example, for lumbar puncture or pre adenosine for supraventricular tachycardia; as opposed to the main sedation agent for other procedures. The combination of Morphine and Midazolam as the sole agents for a sedation were only used three times in total during the period of the study.

\section{Complications}

Hypoxia was the most common complication followed by hypotension and vomiting at $75 \%, 9 \%$ and $8 \%$ of all complications respectively. The Other category was two cases of transient rash and one case of a brief and self-terminating run of ventricular tachycardia (VT) (Table 1). There were no recorded aspiration events, cardiac arrests or deaths, however there were two episodes of laryngospasm including one that did not respond to positive pressure ventilation and required intubation but was subsequently discharged at baseline. Other than this, no patient had a recorded clinically evident adverse outcome from ED sedation. There were three patients that had more than one complication: one laryngospasm and secondary hypoxia, one of both hypoxia and hypotension and one that had conscious VT and secondary hypotension and hypoxia. Only one complication has been recorded against each of these patients, despite one patient having three separate complications (but all precipitated by the VT).

The study population was broken into three age ranges, 16 years and younger, 17 to 65 years and those 66 years and older. The proportions of the study population each of these groups represents was $30 \%, 53 \%$ and $17 \%$ with the complications in each group being: $2.4 \%, 3.4 \%$ and $6.5 \%$ respectively.

If the form indicated the Consultant performed a role or was present, then the sedation was considered a Consultant sedation. Of the 1793 sedations recorded, 948 were Consultant sedations. Complications by sedationist seniority were $1.9 \%$ Registrars (16/845, 95\%CI 1.1-3.1) and 4.1\% Consultants (39/948, 95\%CI 3.0-5.6). Consultants are available from 0800 until nominally midnight (but often later). Many senior ED Registrars will undertake uncomplicated sedations independently particularly between midnight and $0800 \mathrm{hrs}$.

\section{Fasting status}

There were five episodes of vomiting recorded. Two episodes in each of the 2-6 hrs and $>6 \mathrm{hrs}$ fasting groups and one in which a fasting status was not recorded (Table 2).

\section{Discussion}

Orthopaedic procedures (fracture and joint manipulation) were the most common reason for sedation with rates broadly comparable to previous Australasian studies. ${ }^{3}$ This was followed by suturing and DC cardioversion. Notably sedation for cardioversion is significantly more common than reported by Bell et al: ${ }^{3} 11.8 \%$ (95\%CI 9.2-13.3) compared to $5.6 \%$ (95\%CI 4.4-7) age 17-64 years and $20.0 \%$ (95\% CI $15.9-24.8)$ compared to $8.6 \%(95 \% \mathrm{CI}$ 6.3-11.6) in those aged $\geq 65$ years $(\mathrm{P}<0.0001$ in both groups). This possibly reflects the increasing use of the Direct Oral Anticoagulants with their relatively dependable anticoagulation and is potentially an area of further investigation.

A range of medications were used to achieve adequate sedation and appeared nuanced to the patient and their condition. The medications used also reflects the evolution in ED sedation with ketamine, propofol and fentanyl largely replacing older agents such as morphine and midazolam which while still used occasionally, are now very rarely used in combination. This is supported by contrasting the usage of midazolam and morphine in the study by Taylor et al. ${ }^{1}$ where midazolam was used in $23.8 \%$ (95\% CI 22.5 $25.5)$ of sedations versus $10.3 \%(\mathrm{P}<0.00001)$ and morphine in $7.9 \%$ (95\% CI $6.9-9.0)$ of sedations versus $1.5 \%(\mathrm{P}<0.00001)$. Taylor ${ }^{1}$ noted in his study that both morphine and midazolam were associated with sedation related complications, therefore the difference in sedation medications likely partially explains the difference in sedation complications between the two studies. Minor procedures were often done under nitrous oxide, children $\leq 16$ years often receiving IM ketamine, IV ketamine for older children and fentanyl/propofol for most adults. It is interesting to note the use of propofol alone in $12.2 \%(218 / 1793)$ of sedations. In this sub-group, 51.4\% (112/218) were joint reduction, $27.5 \%$ DC cardioversion, $15.6 \%$ fracture reduction and the remainder either 
suturing or other painful procedures. Given propofol has no analgesia qualities, this adds more evidence to the on-going ED debate about adequate analgesia in emergency. ${ }^{4,5}$

As the study progressed it became apparent that many of the complications were potentially preventable. Patients that became hypoxic and hypotensive often had no or minimal oxygen supplementation or were given large boluses of sedative. Subsequent education sessions to both medical and nursing staff emphasised the approach of ensuring nasal prong oxygen (which also provides capnography and is standard of care) with $15 \mathrm{~L}$ non-rebreather mask, ${ }^{6}$ as well as reducing the dose of propofol to no more than 0.5 $\mathrm{mg} / \mathrm{kg}$ per dose and titrating to level of sedation. It was emphasised in the education sessions that in a physiologically normal patient propofol (https://www.drugs.com/pro/propofol.html) takes approximately 40 seconds to achieve maximal affect when given intravenously, meaning the extra one or two doses might make the whole sedation several minutes longer but much safer. Following these education sessions (undertaken in the second and third sixmonth periods and on multiple occasions to capture as many staff as possible), the complications due to hypoxia and hypotension steadily declined to reach a nadir in the $4^{\text {th }}$ period. However unfortunately the low rate of complications was not maintained with the last period complication rate rebounding to $3.1 \%$ of all sedations, largely due to practitioners reverting to pre-education session sedation techniques.

The recorded incidence of serious complications was very low, and similar to other studies ${ }^{7}$ with one episode of laryngospasm requiring intubation, but no recorded deaths, cardiac arrests or aspiration events.

The overall complication rate for this study was 3.1\% (55/1793, 95 CI 2.3-4.0) which is significantly lower $(\mathrm{P}<0.0001)$ than the $7.2 \%(188 / 2426,95 \%$ CI $6.2-8.2)$ recorded in the 2011 study by Taylor et al. ${ }^{1}$ Similar to other studies respiratory events were the most common complication of sedation ${ }^{1,5}$ at The Canberra Hospital, making up $75 \%$ of all complications over the two and a half years of the study.

Consultant lead sedation has a higher rate of complications, but it is unclear if this reflects selection biased increased case complexity or poor sedation practise. This was an unexpected finding and this study was not structured to determine the cause, as such this is an area of potential further research. The low rate of complications in those $\leq 16$ years likely illustrates the safety of the prominent agents used in this group; ketamine and nitrous oxide. Of the thirteen complications recorded in this group, 8 were associated with ketamine and nitrous oxide of which half were vomiting. The remainder were associated with propofol use in older children. The higher complication rate in the $>66$ yrs group is likely due to a combination of decreasing patient physiologic reserve, comorbidities, greater sensitivity to sedative agents, combined with a smaller volume of distribution. ${ }^{1}$

Unfortunately, 22\% (396/1793) of patients did not have a fasting status recorded. Of those with a recorded fasting status, $53.9 \%$ (756/1403) were fasted less than six hours. This reflects the reality of ED practise, in that acute painful conditions are treated on an urgent basis, rather than delay care in an often-overcrowded ED to adhere to general anaesthetic fasting regimens. Notably there were only five instances of vomiting post sedation recorded over the study period and no recorded aspiration events. The five episodes of vomiting appeared to bear no association with length of fasting as supported by other research papers. ${ }^{8-10}$ Of note, four of these episodes of vomiting were after ketamine sedation, and one after nitrous oxide sedation for application of a plaster of paris cast. Both agents are well recognised to cause this complication. ${ }^{8}$ Interestingly there were no episodes of vomiting in the group (79 cases) recorded as having been fasted for less than 2 hours.

Table 1. Sedation complications.

\begin{tabular}{|c|c|c|c|c|c|c|c|c|c|c|c|c|c|c|}
\hline \multirow[b]{2}{*}{ Hypoxia } & \multicolumn{2}{|c|}{$\begin{array}{l}\text { May/Dec } \\
2015\end{array}$} & \multicolumn{2}{|c|}{$\begin{array}{l}\text { Dec/May } \\
2016\end{array}$} & \multicolumn{2}{|c|}{$\begin{array}{c}\text { May/Dec } \\
2016\end{array}$} & \multicolumn{2}{|c|}{$\begin{array}{c}\text { Dec/May } \\
2017\end{array}$} & \multicolumn{2}{|c|}{$\begin{array}{c}\text { May/Dec } \\
2017\end{array}$} & \multicolumn{2}{|c|}{ Total } & \multicolumn{2}{|c|}{ Taylor et al. ${ }^{1}$} \\
\hline & 8 & $2.7 \%$ & 11 & $3.1 \%$ & 10 & $2.6 \%$ & 4 & $1 \%$ & 9 & $2.5 \%$ & $42 / 1793$ & $2.3 \%$ & $111 / 2611$ & $4.25 \%$ \\
\hline Hypotension & 1 & $0.3 \%$ & 2 & $0.6 \%$ & 1 & $0.3 \%$ & 0 & $0 \%$ & 2 & $0.6 \%$ & $6 / 1793$ & $0.3 \%$ & $41 / 2587$ & $1.6 \%$ \\
\hline Vomit & 2 & $0.7 \%$ & 1 & $0.3 \%$ & 1 & $0.3 \%$ & 1 & $0.3 \%$ & 0 & $0 \%$ & $5 / 1793$ & $0.3 \%$ & $42 / 2614$ & $1.6 \%$ \\
\hline Laryngospasm & 0 & $0 \%$ & 0 & $0 \%$ & 1 & $0.3 \%$ & 0 & $0 \%$ & 1 & $0.3 \%$ & $2 / 1793$ & $0.1 \%$ & 2/2611 & $0.08 \%$ \\
\hline Other & 1 & $0.3 \%$ & 2 & $0.6 \%$ & 1 & $0.3 \%$ & 0 & $0 \%$ & 0 & $0 \%$ & $4 / 1793$ & $0.2 \%$ & $5 / 2611$ & $0.2 \%$ \\
\hline >1 Complication & 0 & $0 \%$ & 1 & $0.3 \%$ & 1 & $0.3 \%$ & 0 & $0 \%$ & 1 & $0.3 \%$ & - & - & $13 / 2623$ & - \\
\hline Total & 12 & $4.0 \%$ & 15 & $4.1 \%$ & 12 & $3.2 \%$ & 5 & $1.3 \%$ & 11 & $3.1 \%$ & $55 / 1793$ & $3.1 \%$ & $188 / 2613$ & $7.2 \%$ \\
\hline
\end{tabular}

Table 2. Fasting status.

\begin{tabular}{|c|c|c|c|c|c|c|c|c|c|c|c|c|}
\hline \multirow[b]{2}{*}{$<2$ hours } & \multicolumn{2}{|c|}{$\begin{array}{l}\text { May/Dec } \\
2015\end{array}$} & \multicolumn{2}{|c|}{$\begin{array}{c}\text { Dec/May } \\
2016\end{array}$} & \multicolumn{2}{|c|}{$\begin{array}{c}\text { May/Dec } \\
2016\end{array}$} & \multicolumn{2}{|c|}{$\begin{array}{c}\text { Dec/May } \\
2017\end{array}$} & \multicolumn{2}{|c|}{$\begin{array}{c}\text { May/Dec } \\
2017\end{array}$} & \multicolumn{2}{|c|}{ Total } \\
\hline & 11 & $4 \%$ & 22 & $6 \%$ & 19 & $5 \%$ & 16 & $4 \%$ & 11 & $3 \%$ & $79 / 1403$ & $5.6 \%$ \\
\hline 2-6 hours & 100 & $34 \%$ & 114 & $32 \%$ & 138 & $36 \%$ & 169 & $42 \%$ & 156 & $44 \%$ & $677 / 1403$ & $48.3 \%$ \\
\hline$>6$ hours & 122 & $41 \%$ & 135 & $38 \%$ & 132 & $35 \%$ & 141 & $35 \%$ & 111 & $31 \%$ & $641 / 1403$ & $45.7 \%$ \\
\hline Unrecorded & 64 & $22 \%$ & 88 & $25 \%$ & 91 & $24 \%$ & 74 & $19 \%$ & 79 & $22 \%$ & $396 / 1793$ & - \\
\hline
\end{tabular}




\section{Limitations}

It is possible that cases were missed because no form was completed for a sedation. This is unlikely as there was a strong preexisting nursing culture of completing these forms for all sedations. However, there was a perception amongst some staff that nitrous oxide doesn't count and may have been under-represented initially in the database as it was regarded as analgesia and not sedation.

Recording of adverse events by nursing staff is dependent on the scribe nurse accurately recording observations. This is of particular importance with regard to oxygen saturations where there may be an inclination for the scribe nurse to interpret the result and determine whether the reading warrants documentation. There are also the issues with regard to observation reliability, for example the spurious desaturation caused by a BP cuff inflating above the pulse oximeter.

Poor documentation meant that some aspects of the sedations couldn't be studied (e.g. airway assessment) or couldn't be as thoroughly interrogated as the investigators would have preferred (e.g. fasting status).

\section{Conclusions}

ED sedation for painful or unpleasant procedures is frequently undertaken with a range of agents and has relatively few complications compared to previous Australian literature. These complications however appear to be amenable to intervention through education of both nursing and medical staff involved, resulting in an overall reduction in the complication rate. However, this improvement then decayed with time relative to the education sessions.

\section{References}

1. Taylor DM, Bell A, Holdgate A, et al. Risk factors for seda- tion-related events during procedural sedation in the Emergency Department. Emerg Med Australas 2011;23:46673.

2. Australasian College for Emergency Medicine. ACEM Curriculum Framework; 2014. Available from: https://acem.org.au/Content-Sources/Training/How-theFACEM-Training-Program-works/Curriculum-FrameworkSearch Accessed: December 30, 2017.

3. Bell A, Taylor DM, Holdgate A, et al. Procedural sedation practices in Australian Emergency Departments. Emerg Med Australas 2011;23:458-65.

4. Taylor DM, Fatovich DM, Finucci DP, et al. Best-practice pain management in the emergency department: a cluster-randomised, controlled, intervention trial. Emerg Med Australas 2015;27:549-57.

5. Bell A, Treston G, McNabb C, et al. Profiling adverse respiratory events and vomiting when using propofol for emergency department procedural sedation. Emerg Med Austalas 2007;19:405-10.

6. Thomson D, Cowan T, Loten C, et al. High-flow oxygen in patients undergoing procedural sedation in the emergency department: A retrospective chart review. Emerg Med Australas 2017;29:33-9.

7. Bellolio MF, Gilani WI, Barrionuevo P, et al. Incidence of adverse events in adults undergoing procedural sedation in the emergency department: A systemic review and meta-analysis. Acad Emerg Med 2016;23:119-34.

8. Thorpe RJ, Benger J. Pre-procedural fasting in emergency sedation. Emerg Med J 2010;27:253.

9. Sacchetti A, Senula G, Strickland J. Procedural sedation in the community emergency department: initial results of the proSCED registry. Acad Emerg Med 2007;14:41-6.

10. Miller KA, Andolfatto G, Miner JR, et al. Clinical Practice Guideline for Emergency Department Procedural Sedation with Propofol: 2018 Update. Ann Emerg Med 2019;73:470-80. 